\title{
RöKo für Studierende: Kostenfreie Teilnahme, Sonderprogramm und DRG-Mitgliedschaft
}

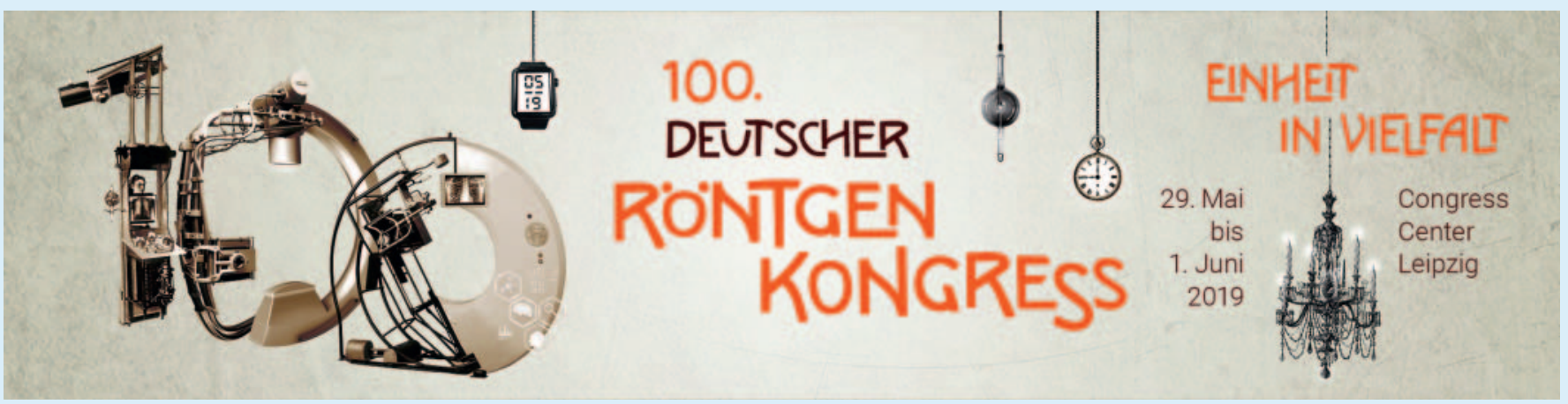

Auch für Medizinstudierende ist der Kongress eine hervorragende Gelegenheit, mit der Vielfalt des Faches und seinen wissenschaftlichen Perspektiven in Kontakt zu treten. Wir laden Sie herzlich zum Kongressbesuch ein - die Teilnahme ist für Studierende kostenfrei. Melden Sie sich online auf roentgenkongress.de an - wählen Sie hierfür die Option „Studenten“ und schicken Sie Ihren Studentenausweis in Kopie an das Kongressbüro. Kurzentschlossene können sich auch vor Ort auf dem Kongressgelände noch registrieren - Studentenausweis zur Vorlage nicht vergessen!

\section{Kongress-Sonderprogramm für Studierende}

Mit seinen hunderten von wissenschaftlichen Vorträgen, Refresher-Kursen und Workshops an vier Kongresstagen ist der RöKo der größte deutschsprachige Radiologiekongress. Daher bieten wir in diesem Jahr speziell für Studierende und Erstbesucher eine Einführungsveranstaltung rund um das Thema „Orientierung beim Kongress“ gleich am ersten Kongresstag an.

Ein ganz besonderes Highlight werden erneut die „Sono4You“-Kurse sein: In diesen Hands-On-Kursen speziell für Studierende lernen Sie Ultraschall direkt am Gerät eben „Hands On“! Da die Teilnehmerzahl stark beschränkt ist, ist eine gesonderte Anmeldung und Buchung für diese Kurse erforderlich. Alle Infos zum Einführungsprogramm für Studierende, zu den Sono4youKursen sowie zur Anmeldung finden Sie auf hellste-koepfe.de > Röntgenkongress 2019.
Zur Einführung in die Interventionelle Radiologie wird es beim 100. RöKo erstmals den Kurs „Flinke Finger cand. med.“ geben. In Kleingruppen können die Studierenden interventionelle Eingriffe an Simulatoren selbst durchführen. Auch hier ist eine gesonderte Anmeldung erforderlich. Infos zu Programm und Anmeldung finden Sie auf hellste-koepfe.de > Röntgenkongress 2019.

\section{Das RöntgenFORUM als erste Anlaufstelle}

Im hinteren Bereich der Halle 2 (Industrieausstellung) wird es im „RöntgenFORUM“ einen Bereich für Studierende und junge Radiologen zum gegenseitigen Kennenlernen und Austausch geben: die Next Generation Lounge. Hier treffen Sie an allen Tagen Ansprechpartner, die Ihnen im „Dschungel“ des umfangreichen Kongressangebots weiterhelfen. An Internet-Terminals können Sie den weiteren Kongressbesuch planen.

\section{www.hellste-koepfe.de}

Viele Infos rund um Studierende beim Röntgenkongress finden Sie auch unter www.hellste-koepfe.de, dem Internetportal der DRG für junge Radiologen und Studierende, die im Laufe der kommenden Wochen noch erweitert werden - zum Beispiel um die Kongresstipps für Erstbesucher!

\section{Werden Sie Teil einer großen Wissensgemein- schaft!}

Alle Studierenden, die sich zum 100. Deutschen Röntgenkongress anmelden, egal ob über das Stipendienprogramm „die hellsten Köpfe für die Radiologie“ oder als Teilnehmer über die Kongressregistrierung, erhalten erstmals eine kostenfreie Mitgliedschaft in der Deutschen Röntgengesellschaft bis Ende des Jahres 2019. Einfach bei der Anmeldung zum Kongress den aktuellen Studentenausweis hochladen und schon sind Sie Teil einer großen Wissensgemeinschaft. Die Stipendiaten der hellsten Köpfe müssen nichts weiter tun, da sie bereits zum Kongress angemeldet sind. Alle Unterlagen und Informationen zur Mitgliedschaft erhalten diese im Nachgang des Kongresses. ${ }^{*}$

Die Deutsche Röntgengesellschaft, Gesellschaft für medizinische Radiologie e. V., wurde 1905 in Berlin gegründet und gehört zu den traditionsreichen und bedeutenden medizinischen Gesellschaften. Sie widmet sich der Förderung der Radiologie in allen ihren Bereichen einschließlich der wissenschaftlichen Grundlagenforschung.

Alle weiteren Informationen zur DRG finden Sie auf drg.de > Mitglied werden.

*Die kostenfreie Mitgliedschaft gilt nur bei erstmaliger Anmeldung als Studierender oder Stipendiat zum Deutschen Röntgenkongress. Bei wiederholter Teilnahme wird die Mitgliedschaft kostenpflichtig. Sie kann jedoch zu jeder Zeit wieder gekündigt werden. 